\title{
PENERAPAN METODE SIMPLE ADDITIVE WEIGHTING (SAW) DALAM SELEKSI CALON KARYAWAN
}

\author{
Nia Nuraeni \\ STMIK Nusa Mandiri Jakarta \\ Jl. Kramat Raya No. 18 Jakarta Pusat, 021-31908575 \\ e-mail: niyut 1479@yahoo.com
}

\begin{abstract}
Abstrak
PT. Dolarindo Intravalas Primatama adalah perusahaan jasa keuangan non-perbankan di bidang money changer yang telah berdiri sejak 1999. Dalam proses pengembangan bisnis, PT Dollarindo membutuhkan tenaga kerja yang memiliki tingkat profesionalisme yang cukup. Proses rekrutmen adalah proses yang sangat awal yang menentukan prosesnya, sebuah tes seleksi yang efektif dan efisien adalah kuncinya. Penelitian ini menggunakan metode Simple Additive Weighting (SAW) yang sering juga dikenal dengan metode penjumlahan tertimbang. Konsep dasar metode Saw adalah menemukan jumlah penilaian kinerja tertimbang pada setiap alternatif pada semua atribut. Data yang ditampilkan pada penelitian ini sebanyak 30 data calon Karyawan (dari \pm 281 calon Karyawan). Pemanfaatan metode ini akan menghasilkan sistem pendukung keputusan yang dapat membantu tim rekrutmen dalam melakukan proses seleksi di PT. Dolarindo Intravalas Primatama, sehingga bisa mempermudah proses pemilihan karyawan sesuai dengan kebutuhan. Berdasarkan dari hasil penelitian yang telah dilakukan maka dapat disimpulkan bahwa penggunaan metode Simple Additive Weighting (SAW) memiliki nilai keakuratan tinggi (sebesar 81\%), sehingga dapat diaplikasikan dalam proses perekrutan calon karyawan dibandingkan dengan penilaian tes seleksi karyawan secara manual.
\end{abstract}

Kata Kunci: Pemilihan Karyawan, Pengambilan Keputusan, Simple Additive Weighting

\begin{abstract}
PT. Dolarindo Intravalas Primatama is a non-banking financial services company in the field of money changer which has been established since 1999. In the process of business development, PT Dollarindo requires a workforce that has a sufficient level of professionalism. the recruitment process is a very early process that determines the process, an effective and efficient selection test is the key. This research uses Simple Additive Weighting (SAW) method which is often also known as weighted summing method. The basic concept of the Saw method is to find a weighted sum of performance ratings on each alternative on all attributes. The data that exist in this research as many as 30 data prospective Employees (from \pm 281 prospective employees). The utilization of this method will produce a decision support system that can assist the recruitment team in conducting the selection process at PT. Dolarindo Intravalas Primatama, so that it can simplify the process of selecting the appropriate employee with the needs. Based on the result of the research, it can be concluded that the use of Simple Additive Weighting (SAW) method has high accuracy value (81\%), so it can be applied in the recruitment process of employee candidates compared to the assessment of employee selection test manually.

Keywords: Decision Maker, Employee Selection, Simple Additive Weighting
\end{abstract}

\section{Pendahuluan}

Proses rekrutmen ini adalah proses mencari, menemukan, mengajak dan menetapkan sejumlah orang dari dalam maupun dari luar perusahaan sebagai calon tenaga kerja dengan karakteristik tertentu seperti yang telah ditetapkan dalam perencanaan sumber daya manusia. Hasil yang didapatkan dari proses rekrutmen adalah sejumlah tenaga kerja yang akan memasuki proses seleksi, yakni proses untuk menentukan kandidat yang mana yang paling layak untuk mengisi jabatan tertentu yang tersedia di perusahaan, 
setelah diadakan perencanaan SDM, dan analisis serta klasifikasi pekerjaan. Proses Rekrutmen ini dimulai dengan mencari calon pelamar dan berakhir dengan diserahkannya surat lamaran kerja pelamar ke organisasi yang melakukan rekrutmen (Setiani, 2013). Setelah Rekrutmen, proses selanjutnya adalah proses penyeleksian pelamar kerja hingga terpilinnya pelamar kerja tersebut menjadi karyawan untuk mengisi posisi yang dibutuhkan. PT. Dolarindo Intravalas Primatama merupakan sebuah perusahaan layanan keuangn non perbankan dibidang pertukaran mata uang asing (money changer). Untuk perkembangan usaha yang saat ini sudah mencapai 10 outlet yang tersebar di daerah DKI Jakarta dan Bandung maka dibutuhkan sumber daya manusia yang memadai, untuk itu PT Dolarindo melakukan rekrutmen karyawan yang melalui beberapa tahap seleksi berdasarkan persyaratan dan tes seleksi adapun beberapa tes dan persyaratan bagi calon karyawannya, adapun beberapa persyaratan dan tes tersebut berupa: usia, pendidikan (Minimal SMA/Sederajat), status (menikah/belum menikah), psikotes, wawancara dan pengalaman bekerja.

Dalam proses rekrutmen tersebut PT Dolarindo seringkali menemui kesalahan baik yang berskala besar maupun kecil ( nama akhir penulis, tahun) yang pada akhirnya dapat mempengaruhi pengambilan keputusan. Terdapat beberapa masalah seperti belum ada ketetapan kriteria dan bobot yang digunakan sebagai acuan pasti dalam penilaian seleksi masuk karyawan, tidak ada nilai penunjang dari setiap persyaratan yang diajukan kepada calon karyawan, pengolahan datanya yang dilakukan secara manual dan tanpa metode apapun sehingga memungkinkan terjadinya perubahan kriteria dan nilai pada setiap kali melakukan seleksi karyawan (Ashari, 2015). Pekembangan sistem informasi saat ini memungkinkan perusahaan-perusahan berkembang untuk memanfaatkan metodemetode terkomputerisasi yang dapat memecahkan permasalahan seperti yang dialami oleh PT. Dolarindo, salah satu sistem penunjang keputusan yang sangat mudah digunakan dan dapat dilihat langsung hasil dari penelitiannya ialah sistem Simple Additive Weighting (SAW) (Setiaji, 2014).Metode SAW sering juga dikenal istilah metode penjumlahan terbobot. Konsep dasar metode SAW adalah mencari penjumlahan terbobot dari rating kinerja pada setiap alternatif pada semua atribut. Metode SAW membutuhkan proses normalisasi matriks keputusan $(X)$ ke suatu skala yang dapat dibandingkan dengan semua ranting alternatif yang ada. (Abadi, Latifah, Kunci, Pendukung Keputusan, \& Kinerja Karyawan, 2016). Berdasarkan hasil penelitian system pendukung keputusan dengan menggunakan SAW dapat membantu pihak pengambil keputusan dalam menentukan alternative terbaik yaitu calon karyawan yang tepat (Abadi et al., 2016).

\section{Metode Penelitian}

Penelitian ini dilakukan dengan cara mengumpulkan data-data yang berhubungan dengan permasalahan yang dibahas sehingga dapat membantu menyelesaikan permasalahan. Adapun cara pengumpulan data-data tersebut dilakukan dengan cara sebegai berikut

a. Obervasi

Penulis melakukan pengumpulan data dengan melakukan pengamatan langsung terhadap obyek yang diteliti dengan instansi terkait untuk mengumpulkan data dan informasi yang berkaitan dengan permasalahan yang ada. Informasi yang berkaitan yaitu dengan pengamatan langsung di PT. Dolarindo Intravalas Primatama mengenai proses jalannya penilaian seleksi karyawan. Dari hasil observasi diketahui macam-macam kriteria yang digunakan dalam proses rekrutmen diantaranya; Usia calon karyawan, pendidikan, status, hasil psikotes, hasil wawancara dan pengalaman. Jumlah calon karyawan yang melamar pada saat observasi sebanyak \pm 281 calon karyawan yang tersebar di 10 outlet perusahaan yang ada di Jakarta dan Bandung.

b. Wawancara

Penulis melakukan Tanya jawab terhadap bagian HRD yang berkaitan langsung dengan proses rekrutmen dan seleksi calon karyawan di PT. Dolarindo Intravalas Primatama.

c. Studi Pustaka

Penulis mempelajari sumber-sumber buku serta jurnal ilmiah yang berkaitan untuk dikutip sebagai acuan teori untuk mendukung penulisan penelitian ilmiah ini. 
Metode penelitian yang penulis gunakan ialah metode Simple Additive Weighting (SAW). Adapun Langkah-langkah penyelesaian metode Simple Additive Weighting (SAW) adalah sebagai berikut:

a. Menetukan kriteria-kriteria yang akan dijadikan acuan dalam pengambilan keputusan, yaitu $\mathrm{Ci}$.

b. Menetukan rating kecocokan setiap alternatif pada setiap kriteria.

c. Membuat matriks keputusan berdasarkan kriteria (Ci), kemudian melakukan normalisasi matriks berdasarkan persamaan yang disesuaikan dengan jenis atribut (atribut keuntungan ataupun atribut biaya) sehingga diperoleh matriks ternormalisasi R.

d. Hasil akhir proses perankingan yaitu penjumlahan dari perkalian matriks ternormalisasi $\mathrm{R}$ dengan vektor bobot sehinggadiperoleh nilai terbesar yang dipilih sebagai alternatif terbaik (Ai) sebagai solusi. (Wahyudi et al., 2015).

$r_{i j}=\left\{\begin{array}{l}\frac{X_{i j}}{\operatorname{Max} X_{i j}} \\ \frac{\operatorname{Min} X_{i j}}{X_{i j}}\end{array}\right.$

Keterangan:

rij = nilai rating kinerja ternormalisasi

Xij = nilai atribut yang dimiliki dari setiap kriteria

Max $\mathrm{Xij}=$ nilai terbesar dari setiap kriteria

Min $\mathrm{Xij}=$ nilai terkecil dari setiap kriteria
Benefit $=$ jika nilai terbesar adalah nilai terbaik

Cost $=$ jika nilai terkecil adalah nilai terbaik

Dimana rij adalah rating ternormalisasi dari alternatif Ai pada atribut $\mathrm{Cj} ; \mathrm{i}=1,2 \ldots, \mathrm{m}$ dan $j=1,2 \ldots, n$. Nilai prefensi untuk setiap alternatif $(\mathrm{Vi})$ diberikan sebagai:

$V i=\sum_{j=1}^{n}\left(w_{j} r_{i j}\right)$

Keterangan:

$\mathrm{Vi}=$ ranking untuk setiap alternatif

$\mathrm{Wj}=$ nilai bobot dari setiap kriteria

rij = nilai rating kinerja ternormalisasi

Nilai Vi yang lebih besar mengidentifikasikan bahwa alternatif Ai lebih dipilih

\section{Hasil dan Pembahasan}

\subsection{Data Riset}

Berdasarkan data yang diperoleh dari PT Dolarindo Intravalas Primatama tahun 2017, maka dapat diperoleh data calon Karyawan seleksi yang tersebar di 10 outlet di Jakarta dan Bandung untuk selanjutnya di convert kedalam nilai bobot. Data yang ditampilkan pada penelitian ini sebanyak 30 data calon Karyawan (dari \pm 281 calon Karyawan) sehingga diperoleh data sebagai berikut.

Tabel 1. Data Calon Karyawan PT. Dolarindo intravalas Primatama

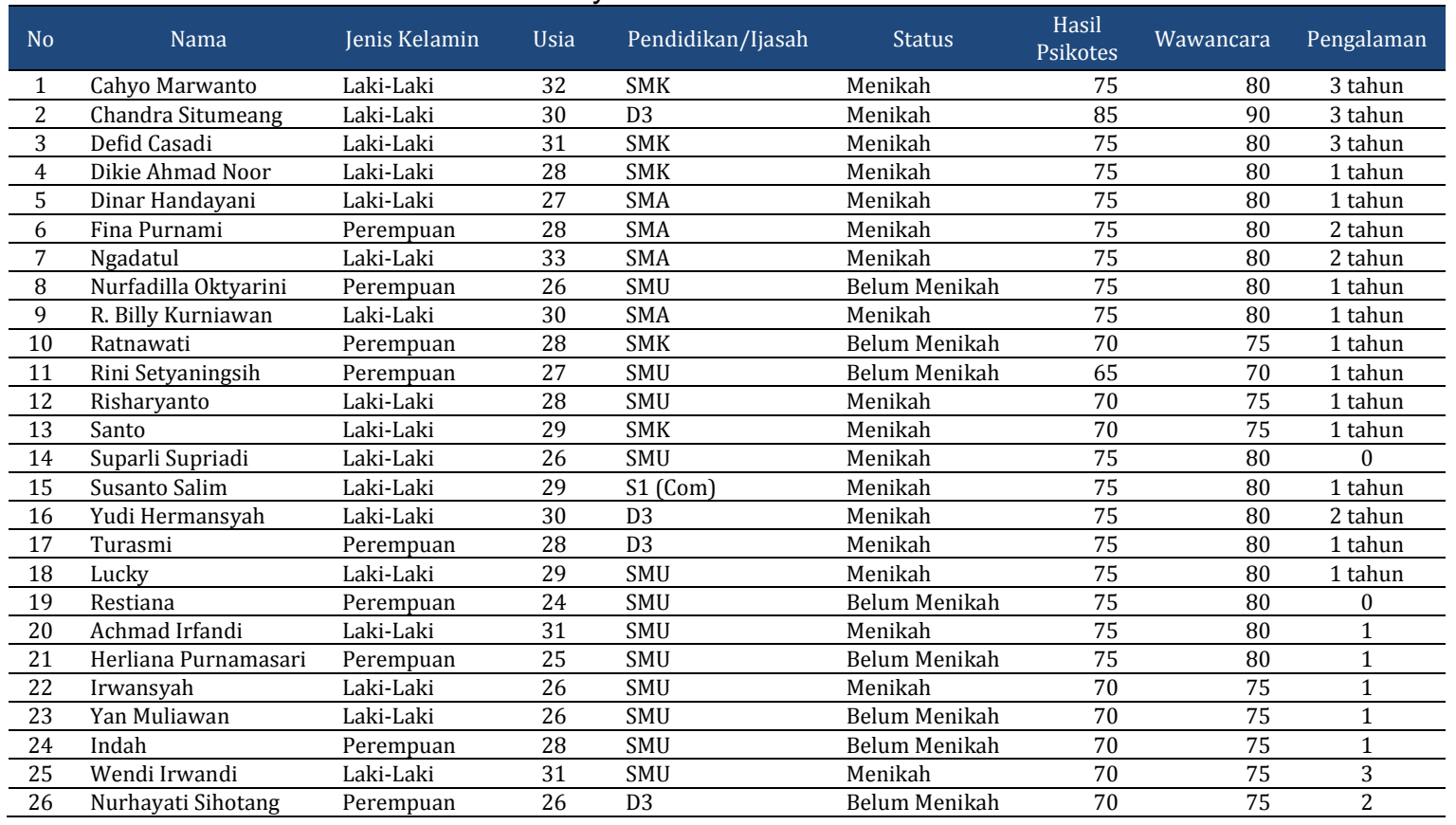

JURNAL SWABUMI Vol.6 No.1, Maret 2018: 63-71 


\begin{tabular}{ll|lllllrr}
\hline No & \multicolumn{1}{c|}{ Nama } & Jenis Kelamin & Usia & Pendidikan/Ijasah & Status & Hasil & Wawancara & Pengalaman \\
\hline 27 & Sylven Siurensia & Perempuan & 28 & S1 & Belum Menikah & 75 & 80 \\
\hline 28 & Anisa & Perempuan & 26 & SMA & Belum Menikah & 75 & 80 \\
\hline 29 & Safitri & Perempuan & 32 & SMK & Menikah & 75 & 80 \\
\hline 30 & Ridwan & Laki-Laki & 32 & SMK & Menikah & 85 & 2 \\
\hline
\end{tabular}

Sumber : Data Primer diolah Tahun 2017

\subsection{Pengolahan Data Menggunakan Metode Simple Additive Weighting (SAW)}

Setelah data calon Karyawan diperoleh, selanjutnya adalah melakukan perhitungan dengan data tersebut dengan metode SAW. Untuk menganalisa lulus atau tidaknya calon Karyawan, dapat dilakukan dengan langkahlangkah sebagai berikut:

a. Menentukan kriteria-kriteria yang akan dijadikan acuan dalam pengambilan keputusan, yaitu $\mathrm{Ci}$.

b. Menentukan rating kecocokan setiap alternatif pada setiap kriteria.

c. Membuat matriks keputusan berdasarkan kriteria $(\mathrm{Ci})$, kemudian melakukan normalisasi matriks berdasarkan persamaan yang disesuaikan dengan jenis atribut (atribut keuntungan ataupun atribut biaya) sehingga diperoleh matriks ternormalisasi $\mathrm{R}$.

d. Hasil akhir diperoleh dari proses perankingan yaitu penjumlahan dari perkalian matriks ternormalisasi $R$ dengan vektor bobot sehingga diperoleh nilai terbesar yang dipilih sebagai alternatif terbaik (Ai) sebagai solusi.

1. Menentukan kriteria-kriteria yang akan dijadikan acuan dalam pengambilan keputusan, yaitu $\mathrm{Ci}$.

Setelah memperoleh data calon Karyawan selanjutnya penulis menentukan kriteriakriteria sebagai acuan dalam pengambilan keputusan, kriteria pada pengambilan keputusan untuk calon Karyawan berdasarkan formulir yang disediakan oleh pihak PT. Dolarindo Intravalas Primatama. Dari formulir tersebut penulis memperoleh data seperti pada Tabel 1. dan dari Tabel 1 penulis menentukan nilai crips yang di sesuaikan dengan kriteria-kriteria. Sehinga diperoleh nilai crips seperti tabel dibawah ini

Tabel 2. Keterangan nilai kriteria dan bobot

\begin{tabular}{|c|c|c|}
\hline Kriteria & Nilai & Bobot \\
\hline \multirow{5}{*}{ Usia } & $19-23$ & 4 \\
\hline & $24-27$ & 3 \\
\hline & $28-30$ & 2 \\
\hline & $31-33$ & 1 \\
\hline & $>34$ & 0 \\
\hline \multirow{3}{*}{ Pendidikan } & $\mathrm{S} 1$ & 4 \\
\hline & D3 & 3 \\
\hline & SMA/SMK & 2 \\
\hline \multirow{2}{*}{ Status } & Belum Menikah & 3 \\
\hline & Menikah & 2 \\
\hline \multirow{5}{*}{ Psikotes } & $80-100$ & 4 \\
\hline & $65-79$ & 3 \\
\hline & $50-75$ & 2 \\
\hline & $25-49$ & 1 \\
\hline & $0-24$ & 0 \\
\hline \multirow{5}{*}{ Wawancara } & $80-100$ & 4 \\
\hline & $65-79$ & 3 \\
\hline & $50-75$ & 2 \\
\hline & $25-49$ & 1 \\
\hline & $0-24$ & 0 \\
\hline \multirow{4}{*}{ Pengalaman } & 3 Tahun & 4 \\
\hline & 2 Tahun & 3 \\
\hline & 1 Tahun & 2 \\
\hline & $<1$ Tahun & 1 \\
\hline
\end{tabular}

Sumber : Data dari PT Dolarindo Intravalas Primatama

Menentukan rating kecocokan setiap alternatif pada setiap kriteria.

Setelah data kriteria dan alternatif diperoleh selanjutnya penulis menentukan rating kecocokan untuk setiap kriteria pada setiap alternatif sehingga diperoleh tabel sebagai berikut:

Tabel 3. Data calon tenaga karyawan dan nilai crips

\begin{tabular}{|c|c|c|c|c|c|c|c|}
\hline No & Nama Karywan & Usia & Pendidikan/ljasah & Status & Hasil Psikotes & Wawancara & Pengalaman \\
\hline 1 & Cahyo Marwanto & 1 & 2 & 2 & 3 & 4 & 4 \\
\hline 2 & Chandra Situmeang & 2 & 3 & 2 & 4 & 4 & 4 \\
\hline 3 & Defid Casadi & 1 & 2 & 2 & 3 & 4 & 4 \\
\hline 4 & Dikie Ahmad Noor & 2 & 2 & 2 & 3 & 4 & 2 \\
\hline 5 & Dinar Handayani & 3 & 2 & 2 & 3 & 4 & 2 \\
\hline 6 & Fina Purnami & 2 & 2 & 2 & 3 & 4 & 3 \\
\hline 7 & Ngadatul & 1 & 2 & 2 & 3 & 4 & 3 \\
\hline 8 & Nurfadilla Oktyarini & 3 & 2 & 3 & 3 & 4 & 2 \\
\hline 9 & R. Billy Kurniawan & 2 & 2 & 2 & 3 & 4 & 2 \\
\hline 10 & Ratnawati & 2 & 2 & 3 & 3 & 3 & 2 \\
\hline 11 & Rini Setyaningsih & 3 & 2 & 3 & 3 & 3 & 2 \\
\hline 12 & Risharyanto & 2 & 2 & 2 & 3 & 3 & 2 \\
\hline
\end{tabular}

JURNAL SWABUMI Vol.6 No.1, Maret 2018: 63-71 


\begin{tabular}{|c|c|c|c|c|c|c|c|}
\hline 13 & Santo & 2 & 2 & 2 & 3 & 3 & 2 \\
\hline 14 & Suparli Supriadi & 3 & 2 & 2 & 3 & 4 & 1 \\
\hline 15 & Susanto Salim & 2 & 4 & 2 & 3 & 4 & 2 \\
\hline 16 & Yudi Hermansyah & 2 & 3 & 2 & 3 & 4 & 3 \\
\hline 17 & Turasmi & 2 & 3 & 2 & 3 & 4 & 2 \\
\hline 18 & Lucky & 2 & 2 & 2 & 3 & 4 & 2 \\
\hline 19 & Restiana & 3 & 2 & 3 & 3 & 4 & 1 \\
\hline 20 & Achmad Irfandi & 1 & 2 & 2 & 3 & 4 & 2 \\
\hline 21 & Herliana Purnamasari & 3 & 2 & 3 & 3 & 4 & 2 \\
\hline 22 & Irwansyah & 3 & 2 & 2 & 3 & 3 & 2 \\
\hline 23 & Yan Muliawan & 3 & 2 & 3 & 3 & 3 & 2 \\
\hline 24 & Indah & 2 & 2 & 3 & 3 & 3 & 2 \\
\hline 25 & Wendi Irwandi & 1 & 2 & 2 & 3 & 3 & 4 \\
\hline 26 & Nurhayati Sihotang & 3 & 3 & 3 & 3 & 3 & 3 \\
\hline 27 & Sylven Siurensia & 2 & 4 & 3 & 3 & 4 & 3 \\
\hline 28 & Anisa & 3 & 2 & 3 & 3 & 4 & 3 \\
\hline 29 & Safitri & 1 & 2 & 2 & 3 & 4 & 3 \\
\hline 30 & Ridwan & 1 & 2 & 2 & 4 & 4 & 3 \\
\hline
\end{tabular}

Sumber : Data Primer diolah Tahun

2. Membuat matriks keputusan

berdasarkan kriteria (Ci)

Setelah menentukan nilai crips selanjutnya melakukan normalisasi matriks berdasarkan persamaan yang disesuaikan dengan jenis atribut (atribut keuntungan ataupun atribut biaya) sehingga diperoleh

$=\frac{\text { Nilai } R}{\text { Nilai Maksimal Per Kriteria }}$

Sehingga diperoleh data sebagai berikut: matriks ternormalisasi R. Dengan rumus sebagai berikut:

Tabel 4. Normaliasasi data calon Karyawan

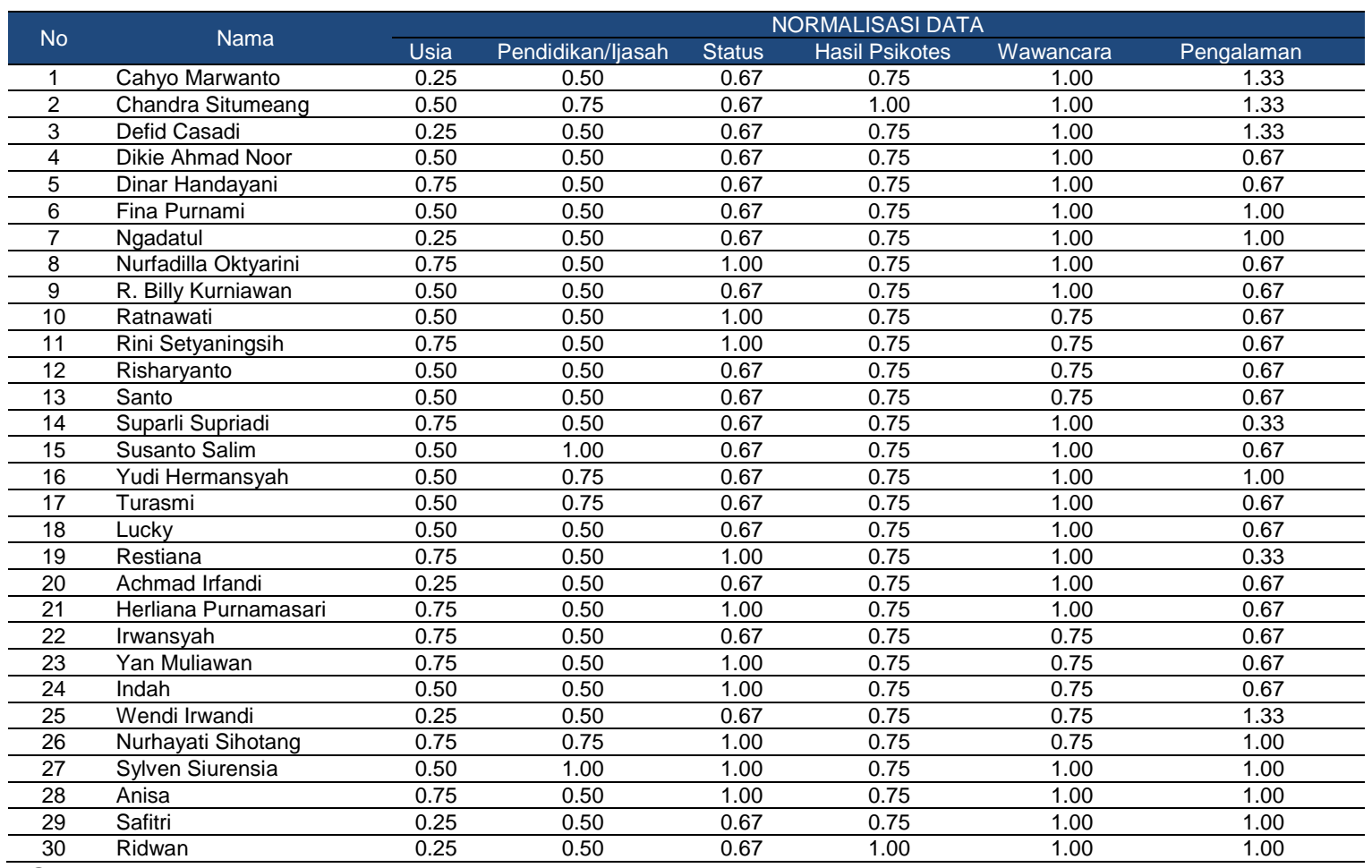

Sumber : Data Primer diolah Tahun 2017

Keterangan dari tabel diatas adalah data dari setiap kriteria dibagikan dengan nilai maksimum dari masing-masing kriteria sehingga diperoleh nilai yang sesuai pada
Tabel 4. sehingga diperoleh matrik nilai normalisasi sebagai berikut: 


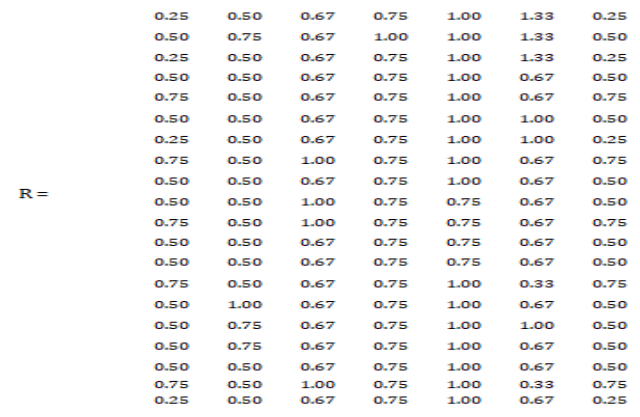

Pengambil keputusan memberikan bobot, berdasarkan tingkat kepentingan masingmasing kriteria yang dibutuhkan (Sundari \& Taufik, 2014) sebagai berikut:

Vektor bobot: $\mathrm{W}=\left[\begin{array}{llllll}3 & 3 & 3 & 3 & 4 & 3\end{array}\right]$ sehingga diperoleh perkalian dari nilai normalisasi dengan vector bobot yang sudah ditentukan. Hasil perkalian matrik normalisasi nilai dengan vector bobot seperti pada Tabel 5 berikut

Tabel 5. Tabel perkalian nilai normalisasi dengan vector bobot

\begin{tabular}{|c|c|c|c|}
\hline No & Nama & Usia & Pendidik \\
\hline 1 & Cahyo Marwanto & 0.75 & 1 \\
\hline 2 & Chandra Situmeang & 1.50 & 2 \\
\hline 3 & Defid Casadi & 0.75 & 1 \\
\hline 4 & Dikie Ahmad Noor & 1.50 & 1 \\
\hline 5 & Dinar Handayani & 2.25 & 1 \\
\hline 6 & Fina Purnami & 1.50 & 1 \\
\hline 7 & Ngadatul & 0.75 & 1 \\
\hline 8 & Nurfadilla Oktyarini & 2.25 & 1 \\
\hline 9 & R. Billy Kurniawan & 1.50 & 1 \\
\hline 10 & Ratnawati & 1.50 & 1 \\
\hline 11 & Rini Setyaningsih & 2.25 & 1 \\
\hline 12 & Risharyanto & 1.50 & 1 \\
\hline 13 & Santo & 1.50 & 1 \\
\hline 14 & Suparli Supriadi & 2.25 & 1 \\
\hline 15 & Susanto Salim & 1.50 & 3 \\
\hline 16 & Yudi Hermansyah & 1.50 & 2 \\
\hline 17 & Turasmi & 1.50 & 2 \\
\hline 18 & Lucky & 1.50 & 1 \\
\hline 19 & Restiana & 2.25 & 1 \\
\hline 20 & Achmad Irfandi & 0.75 & 1 \\
\hline 21 & Herliana Purnamasari & 2.25 & 1 \\
\hline 22 & Irwansyah & 2.25 & 1 \\
\hline 23 & Yan Muliawan & 2.25 & 1 \\
\hline 24 & Indah & 1.50 & 1 \\
\hline 25 & Wendi Irwandi & 0.75 & 1 \\
\hline 26 & Nurhayati Sihotang & 2.25 & 2 \\
\hline 27 & Sylven Siurensia & 1.50 & 3 \\
\hline 28 & Anisa & 2.25 & 1 \\
\hline 29 & Safitri & 0.75 & 1 \\
\hline 30 & Ridwan & 0.75 & 1 \\
\hline
\end{tabular}

HASIL PERKALIAN

Sumber : Data Primer diolah Tahun 2017

Hasil akhir diperoleh dari proses perankingan yaitu penjumlahan dari perkalian matriks ternormalisasi $\mathrm{R}$ dengan vektor bobot sehingga diperoleh nilai terbesar yang dipilih sebagai alternatif terbaik (Ai) sebagai solusi, berdasarkan Tabel 5 dapat diperoleh kesimpulan bahwa nilai diatas atau sama dengan total 14 $(>=14)$ adalah nilai lulus untuk seleksi calon karyawan di PT Dolarindo. Dan nilai kurang dari $14(<14)$ adalah nilai yang tidak lulus dalam proses seleksi karyawan tersebut

\section{Perbandingan Perhitungan Manual dengan SAW}

Setelah hasil perangkingan didapat tahap selanjutnya dalam penelitian ini adalah membandingkan apakah Metode SAW $\begin{array}{llll}\text { Status } & \text { Hasil } & \text { Wawancara Pengalaman }\end{array}$

\begin{tabular}{llll}
2.00 & 2.25 & 4.00 & 4.00 \\
\hline 2.00 & 3.00 & 4.00 & 4.00 \\
\hline 2.00 & 2.25 & 4.00 & 4.00 \\
\hline 2.00 & 2.25 & 4.00 & 2.00 \\
\hline 2.00 & 2.25 & 4.00 & 2.00 \\
\hline 2.00 & 2.25 & 4.00 & 3.00 \\
3.00 & 2.25 & 4.00 & 3.00 \\
2.00 & 2.25 & 4.00 & 2.00 \\
3.00 & 2.25 & 4.00 & 2.00 \\
\hline 3.00 & 2.25 & 3.00 & 2.00 \\
\hline 2.00 & 2.25 & 3.00 & 2.00 \\
\hline 2.00 & 2.25 & 3.00 & 2.00 \\
\hline 2.00 & 2.25 & 4.00 & 2.00 \\
\hline 2.00 & 2.25 & 4.00 & 1.00 \\
\hline 2.00 & 2.25 & 4.00 & 2.00 \\
\hline 2.00 & 2.25 & 4.00 & 3.00 \\
\hline 2.00 & 2.25 & 4.00 & 2.00 \\
\hline 3.00 & 2.25 & 4.00 & 2.00 \\
\hline 2.00 & 2.25 & 4.00 & 1.00 \\
\hline 3.00 & 2.25 & 4.00 & 2.00 \\
\hline 2.00 & 2.25 & 3.00 & 2.00 \\
\hline 3.00 & 2.25 & 3.00 & 2.00 \\
\hline 3.00 & 2.25 & 3.00 & 2.00 \\
2.00 & 2.25 & 3.00 & 2.00 \\
\hline 3.00 & 2.25 & 3.00 & 4.00 \\
\hline 3.00 & 2.25 & 4.00 & 3.00 \\
\hline 3.00 & 2.25 & 4.00 & 3.00 \\
\hline 2.00 & 2.25 & 4.00 & 3.00 \\
\hline 2.00 & 3.00 & 4.00 & 3.00 \\
\hline & 25 & 4.00 & \\
\hline
\end{tabular}

dengan manual memiliki kesamaan atau tidak, jika terdapat kesamaan maka di sebut akurat, jika tidak terdapat kesamaan hasil disebut tidak akurat (Taufiq \& Nugroho, 2016). Tabel perbandingan manual dengan SAW dapat dilihat pada Tabel 6 berikut

Tabel 6. Perbandingan Perhitungan Manual Dengan SAW

\begin{tabular}{clccc}
$N$ & \multicolumn{1}{c}{ Nama } & $\begin{array}{c}\text { Hasil } \\
\text { Manua } \\
\text { I }\end{array}$ & $\begin{array}{c}\text { Hasil } \\
\text { SAW }\end{array}$ & $\begin{array}{c}\text { Perbandinga } \\
n\end{array}$ \\
\hline 1 & Cahyo Marwanto & Lulus & Lulus & Sesuai \\
\hline 2 & Chandra Situmeang & Lulus & Lulus & Sesuai \\
\hline 3 & Defid Casadi & Lulus & Lulus & Sesuai \\
\hline 4 & Dikie Ahmad Noor & Gagal & $\begin{array}{c}\text { Gaga } \\
\text { I }\end{array}$ & Sesuai \\
\hline 5 & Dinar Handayani & Lulus & Gaga & I TidakSesuai \\
\hline 6 & Fina Purnami & Lulus & Lulus & Sesuai \\
\hline 7 & Ngadatul & Gagal & Gaga & I Sesuai \\
\hline 8 & Nurfadilla Oktyarini & Lulus & Lulus & Sesuai \\
\hline 9 & R. Billy Kurniawan & Gagal & Gaga & Sesuai \\
\hline
\end{tabular}

JURNAL SWABUMI Vol.6 No.1, Maret 2018: 63-71 


\begin{tabular}{|c|c|c|c|c|}
\hline $\mathrm{N}$ & Nama & Hasil & Hasil & Perbandinga \\
\hline & & \multicolumn{3}{|c|}{1} \\
\hline \multirow{3}{*}{10} & & & Gaga & \\
\hline & Ratnawati & Gagal & 1 & Sesuai \\
\hline & & & Gaga & \\
\hline \multirow[t]{2}{*}{11} & Rini Setyaningsih & Lulus & I & TidakSesuai \\
\hline & & & Gaga & \\
\hline \multirow[t]{2}{*}{12} & Risharyanto & Gagal & 1 & Sesuai \\
\hline & & & Gaga & \\
\hline \multirow[t]{2}{*}{13} & Santo & Gagal & I & Sesuai \\
\hline & & & Gaga & \\
\hline 14 & Suparli Supriadi & Gagal & I & Sesuai \\
\hline 15 & Susanto Salim & Lulus & Lulus & Sesuai \\
\hline 16 & Yudi Hermansyah & Lulus & Lulus & Sesuai \\
\hline \multirow[b]{2}{*}{17} & & & Gaga & \\
\hline & Turasmi & Lulus & 1 & TidakSesuai \\
\hline \multirow[b]{2}{*}{18} & & & Gaga & \\
\hline & Lucky & Gagal & 1 & Sesuai \\
\hline \multirow[b]{2}{*}{19} & & & Gaga & \\
\hline & Restiana & Lulus & 1 & TidakSesuai \\
\hline \multirow[b]{2}{*}{20} & & & Gaga & \\
\hline & Achmad Irfandi & Gagal & 1 & Sesuai \\
\hline \multirow{2}{*}{21} & $\begin{array}{l}\text { Herliana } \\
\text { Purnamasari }\end{array}$ & Lulus & Lulus & Sesuai \\
\hline & & & Gaga & \\
\hline 22 & Irwansyah & Gagal & 1 & Sesuai \\
\hline \multirow[b]{2}{*}{23} & & & Gaga & \\
\hline & Yan Muliawan & Lulus & 1 & TidakSesuai \\
\hline \multirow{3}{*}{24} & & & Gaga & \\
\hline & Indah & Gagal & 1 & Sesuai \\
\hline & & & Gaga & \\
\hline 25 & Wendi Irwandi & Gagal & I & Sesuai \\
\hline 26 & Nurhayati Sihotang & Lulus & Lulus & Sesuai \\
\hline 27 & Sylven Siurensia & Lulus & Lulus & Sesuai \\
\hline \multirow[t]{2}{*}{28} & Anisa & Lulus & Lulus & Sesuai \\
\hline & & & Gaga & \\
\hline 29 & Safitri & Gagal & 1 & Sesuai \\
\hline 30 & Ridwan & Lulus & Lulus & Sesuai \\
\hline
\end{tabular}

Sumber : Data Primer diolah Tahun 2017

\section{Chart Perbandingan Manual dan SAW}

चESUAI - TIDAK SESUAI

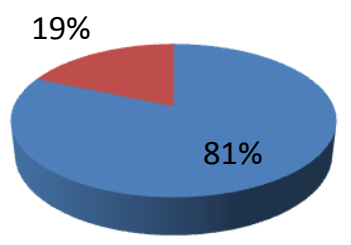

Gambar 1. Chart Perbandingan Perhitungan Manual dengan Metode SAW

Dari hasil perbandingan tersebut diperoleh data bahwa penggunaan metode SAW bisa dijadikan sebagai alternative pengambil keputusan dalam menunjang keputusannya berdasarkan keakuratan sebesar $81 \%$.

\section{Kesimpulan}

Pengguna Sistem Pendukung Keputusan dalam menentukan penilaian tes seleksi calon karyawan dapat membantu dan mempermudah perusahaan dalam hal ini PT Dolarindo Intravalas Primatama dalam menilai tes seleksi calon karyawannya berdasarkan criteria-kriteria yang telah ditentukan yaitu, usia, pendidikan/ijasah, status, psikotes, wawancara dan pengalaman. Berdasarkan dari hasil penelitian yang telah dilakukan maka dapat disimpulkan bahwa penggunaan metode Simple Additive Weighting (SAW) memiliki nilai keakuratan tinggi (sebesar $81 \%$ ), sehingga dapat diaplikasikan dalam proses perekrutan calon karyawan dibandingkan dengan penilaian tes seleksi karyawan secara manual.

\section{Referensi}

Abadi, S., Latifah, F., Kunci, K., Pendukung Keputusan, S., \& Kinerja Karyawan, P. (2016). Decision Support System Penilaian Kinerja Karyawan Pada Perusahaan Menggunakan Metode Simple Additive Weighting. Jurnal TAM (Technology Acceptance Model, 6, 3743.

Ashari,(2015). Penerapan Fuzzy Multiple Criteria Decision Making (MCDM) Dalam Seleksi Calon Karyawan Pada PT. Indomarco Prismatama. Jurnal IImu Komputer, Volume 1, Nomor 1, 2015

http://ilmumanajemenindustri.com (diakses tanggal September 2017).

Setiaji, P. (2014). Sistem Pendukung Keputusan Dengan Metode Simple Additive Weighting Untuk Menentukan Dosen. Universitas Muria Kudus, 1115.

Setiani, B. (2013). Kajian Sumber Daya Manusia Dalam Proses Rekrutmen Tenaga Kerja Di Perusahaan. Jurnal IImiah Widya, 1(1), 38-44. Retrieved from http://ejournal.jurwidyakop3.com/index.php/jur nal-ilmiah/article/view/106

Sundari, S. S., \& Taufik, Y. F. (2014). Pegawai Baru Dengan Menggunakan Metode Simple Additive Weighting ( Saw ). Sisfotenika, Vol. 4, No, 140151.

Taufiq, M. I., \& Nugroho, A. P. (2016). SISTEM PENDUKUNG KEPUTUSAN SELEKSI KARYAWAN MENGGUNAKAN METODE SIMPLE ADDITIVE WEIGHTING PADA PT . PHILIPS SEAFOOD INDONESIA, 1(3), 68-84. 
Wahyudi, S., Suheri, H., H, T. N., Komputer, S., Teknologi, F., \& Masalah, L. B. (2015). Implementasi Sistem Keputusan Pengangkatan Karyawan Tetap Pt . Imanuel Surya Utama Menggunakan Metode Saw, 2(1). 